Methods 295 patients who underwent PPCI from 1/9/2017 4/6/2018 at Nottingham University Hospitals had their records reviewed retrospectively. The patients were assigned to one of 3 groups: 1) Clopidogrel Loading (generally because of HBR), 2) Prasugrel Loading-HBR and 3) Prasugrel Loading nonHBR. The Bleeding Academic Research Consortium (BARC) score was used to evaluate the bleeding episodes during admission and out to 6 weeks at clinic review. Mortality data were also collected.

Results 35 patients received Clopidogrel (group 1). The incidence of any BARC bleeding was $8.6 \%$ and in-hospital mortality was 20\%. 54 patients with HBR received Prasugrel (group 2). The incidence of any BARC bleeding was $16.7 \%$ $(p=0.27$ by chi squared compared to group 1$)$ and in-hospital mortality was $7.4 \% \quad(p=0.078$ by chi squared compared to group 1). 206 patients without HBR characteristics received Prasugrel loading (group 3). The incidence of any BARC bleeding was $6.3 \%$. In-hospital mortality was 5.3\%. (Table 1). Conclusions HBR patients with Prasugrel loading before undergoing PPCI have a numerical increase in the risk of bleeding as compared to those receiving Clopidogrel loading, but this was not statistically significant. Furthermore, most of the bleeding was relatively minor (BARC1-22.2\%, BARC2$55.6 \%$, BARC3a-22.2\%). However, there was a numerically lower in-hospital mortality for patients with HBR loaded with Prasugrel compared to Clopidogrel (although not quite reaching statistical significance). There are limitations with this retrospective analysis and prospective randomised trials looking at Prasugrel loading for patients with HBR undergoing PPCI would be useful. Potentially, STEMI protocols could be significantly simplified if Prasugrel loading for all-comers was deemed to be safe and efficacious.

Conflict of Interest None

\section{LONG TERM OUTCOMES OF ROTATIONAL ATHERECTOMY IN PATIENTS WITH SEVERE LEFT VENTRICULAR SYSTOLIC DYSFUNCTION AND CHRONIC KIDNEY DISEASE: A 10-YEAR UNITED KINGDOM TERTIARY CENTRE EXPERIENCE}

Joon Tan, Pei Jie Chong, Sachin Jadhav, William Smith, Ashan Gunarathne, Akhlaque Uddin. Nottingham University Hospitals NHS Trust, Nottingham, UK

\subsection{6/heartjnl-2021-BCS.60}

Introduction Coronary artery calcification (CAC) is commonly seen in patients undergoing percutaneous coronary intervention (PCI) in the United Kingdom (UK). An aging population with risk factors such as diabetes and chronic kidney disease (CKD) have contributed to the rise in the prevalence of CAC. Despite advancement in PCI and alternative plaque modifying technology, rotational atherectomy (RA) remains an important adjunct to facilitate stent delivery. The UK records the highest use of RA in Europe, with a rate of $3.1 \%$ of total PCI. We report the 10-year experience of RA in a large UK tertiary hospital.

Method This was a single tertiary centre, retrospective study of prospectively collected data on 213 patients who underwent RA PCI between October 2010 to February 2020. Procedural success and complications were assessed. The clinical outcomes evaluated were: target lesion revascularisation (TLR), readmission with heart failure, acute coronary syndrome (ACS) within 1 year, 30-day mortality and 18-month mortality.
Subgroup analysis of outcomes in patients aged more than 80, severe left ventricular dysfunction and chronic kidney disease was performed.

Results Patients had a mean age of $72.9 \pm 8.6$ years. $77.9 \%$ $(n=166)$ were male. $67.6 \%(n=144)$ had hypertension, $35.7 \%$ $(n=76)$ had diabetes, 9.4\% $(n=20)$ were actively smoking, 6.6\% $(n=14)$ had CKD 4-5, and 15\% $(n=32)$ had severe left ventricular systolic dysfunction (LVSD). 51.2\% $(\mathrm{n}=109)$ had prior MI, 34.7\% $(n=74)$ had previous PCI and $20.2 \%$ $(n=43)$ previously had coronary artery bypass grafts. Indications were: acute coronary syndrome $(52.6 \%)$, stable angina (41.3\%) and bailout during STEMI (6.1\%). 75\% were discussed at the MDT prior to RA, and 25\% were ad-hoc PCI. Predominant access was via the radial artery (74.6\%), using

Kaplan-Meier survival curve of patients with chronic kidney disease

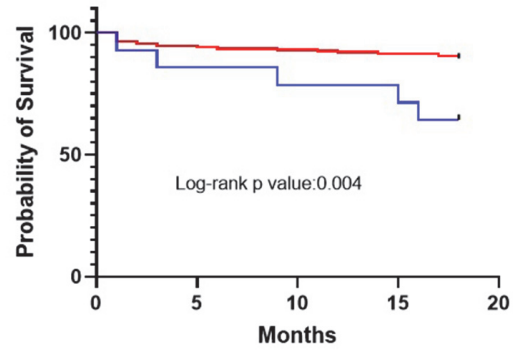

- eGFR $<30$ $+\mathrm{eGFR} \geq 30$

Number at risk

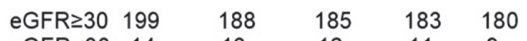

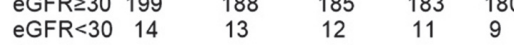

Abstract 60 Figure 1 Kaplan-Meier survival curves of patients with CKD

Kaplan-Meier survival curve of patients with LVEF $<35 \%$ and LVEF $\geq 35 \%$

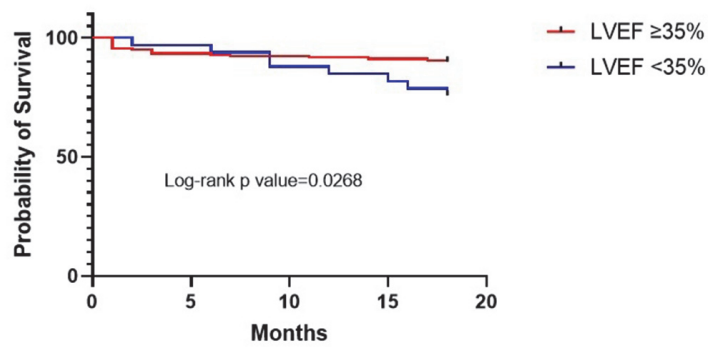

Number at risk

$\begin{array}{lccccc}\mathrm{EF} \geq 35 \% & 180 & 168 & 166 & 165 & 163 \\ \mathrm{EF}<35 \% & 33 & 32 & 31 & 28 & 26\end{array}$

Abstract 60 Figure 2 Kaplan-Meier survival curves of patients with LVEF $<35 \%$

Abstract 60 Table 1 List of complications

\begin{tabular}{|lr|}
\hline Complications & $\mathrm{N}(\%)$ \\
\hline No reflow & $5(2.3)$ \\
Coronary perforation & $9(4.2)$ \\
Aortic dissection & $1(0.5)$ \\
Burr entrapment & $3(1.4)$ \\
Severe bleeding* & $1(0.5)$ \\
Stent thrombosis & $2(0.9)$ \\
Peri-procedural stroke & $0(0)$ \\
Immediate death & $1(0.5)$ \\
\hline & \\
Values are N (\%). & \\
*Bleeding complications as defined by Type 3-5 Bleeding Academic Research Consortium criteria \\
(BARC).
\end{tabular}


Abstract 60 Table 2 Clinical outcomes

\begin{tabular}{|l|l|l|l|l|}
\hline Outcomes & All patients & $\begin{array}{l}\text { Severe LVSD } \\
\text { (EF<35\%) } \\
\mathrm{N}=32\end{array}$ & $\begin{array}{l}\text { CKD 4/5 } \\
\text { (eGFR }<30)\end{array}$ & $\begin{array}{l}\text { Patients above } \\
80 \text { years of age } \\
\mathrm{N}=14\end{array}$ \\
\hline $\begin{array}{l}\mathrm{N}=213 \\
\text { Target vessel } \\
\text { revascularisation }\end{array}$ & $3(1.4)$ & $1(3)$ & $0(0)$ & $0(0)$ \\
\hline $\begin{array}{l}\text { Rehospitalisation } \\
\text { with Ml in 1 year }\end{array}$ & $17(8)$ & $1(3)$ & $2(14.3)$ & $4(7.5)$ \\
\hline $\begin{array}{l}\text { Rehospitalisation } \\
\text { with heart failure } \\
\text { in 1 year }\end{array}$ & $5(2.3)$ & $4(12.5)$ & $1(7)$ & $1(1.9)$ \\
\hline 30 day mortality & $7(0.5)$ & $0(0)$ & $1(7)$ & $2(3.8)$ \\
\hline $\begin{array}{l}\text { 18 month } \\
\text { mortality }\end{array}$ & $28(13.1)$ & $8(25)$ & $5(35.7)$ & $9(17)$ \\
\hline $\begin{array}{l}\text { Major adverse } \\
\text { cardiovascular } \\
\text { events (MACE) }\end{array}$ & $38(1.8)$ & $8(25)$ & $5(35.7)$ & $9(17)$ \\
\hline
\end{tabular}

Values are $\mathrm{N}(\%)$.

MACE defined as composite of target vessel revascularisation, rehospitalisation with MI in 1 year, 30- day mortality and 18 month mortality.

$6 \mathrm{~F}$ sheaths $(60.6 \%)$. $1.5 \mathrm{~mm}$ burr was most frequently used $(63.4 \%)$ but in $14.6 \%$ of cases, burr upsize was required. Additional equipment such as cutting balloons (4.7\%), intravascular ultrasound (13.6\%), microcatheters (58.2\%), temporary pacing wires $(2.3 \%)$ and intra-aortic balloon pumps (1.4\%) were used.Complexity of procedures ranged from RA of unprotected left main stem $(14.6 \%)$, more than 1 vessel RA (2.8\%), chronic total occlusions $(5.2 \%)$ and in-stent restenosis cases (0.9\%). Mean stent diameter was $3.5 \pm 0.8 \mathrm{~mm}$ and mean stent length was $37.6 \pm 23.4 \mathrm{~mm}$. Stents were successfully delivered in $96.2 \%$ of cases, with a complication rate of $10.3 \%$ (table 1). At 18 months, we observed no significant difference in mortality between the age groups $(p=0.26)$. However, patients with eGFR less than $30(35.7 \%, \mathrm{p}=0.004)$ and ejection fraction $<35 \%(17 \%, \mathrm{p}=0.03)$ undergoing $\mathrm{RA}$ had a significantly higher mortality rate at 18 months (figure 1,2).

Conclusions Our study suggest that severe LVSD and CKD 45 may be a predictor for worse outcomes among rotablation patients. However, advanced age does not appear to be associated with poorer outcomes.

Conflict of Interest None

\section{THE INCONSISTENT CHOICES OF INOTROPIC AND VASOPRESSORS AT THE FRONT DOOR IN PATIENTS WITH ISCHAEMIC CARDIOGENIC SHOCK AND ITS IMPACT ON IN-HOSPITAL MORTALITY}

${ }^{1}$ Amanda Shabana, ${ }^{2}$ Farzan Dholoo, ${ }^{3}$ Patrick Tran, ${ }^{3}$ Prithwish Banerjee. ${ }^{1}$ Oxford University Hospitals NHS Foundation Trust; ${ }^{2}$ Royal Berkshire NHS Foundation Trust; ${ }^{3}$ University Hospitals Coventry \& Warwickshire, Coventry, UK

\subsection{6/heartjnl-2021-BCS.61}

Background Despite no evidence of survival benefit, inotropes and vasopressors continue to be routinely used in the setting of acute myocardial infarction with cardiogenic shock (CS). ESC recommends noradrenaline as vasopressor and dobutamine as inotrope of choice. These are only class $\mathrm{IIb}$ recommendations with level $\mathrm{B} / \mathrm{C}$ evidence. Yet on admission, these agents are initiated almost invariably by intensivists. We believe such prescriptions are inconsistent amongst intensivists and linked with adverse outcomes. After all, inattentive use increases the risk of infarct expansion and ventricular arrhythmias. We also hypothesize that some patients with initial CS stabilize after revascularization without needing vasoactive support and are associated with lower mortality rates.

Method In this single-centre retrospective analysis of 116 patients with ischaemic CS, we examined the type of vasoactive agents initiated on admission and their respective baseline characteristics and angiography data (table 1). Four treatment groups were identified (vasopressors- noradrenaline and metaraminol; inotropes- adrenaline, dobutamine and dopamine; combination; no treatment), and analysed in relation to inhospital mortality by adjusted multivariable logistic regression. We also performed a subgroup analysis of the same outcome for individual drugs and their combinations.

Results All vasoactive agents were decided by on-call intensivists. Overall, patients were aged $68 \pm 13$ years, with average systolic BP (SBP) 71 $\pm 16 \mathrm{mmHg}$. As expected, prescriptions of vasoactive agents were highly variable: vasopressors (16\%), inotropes $(15 \%)$, combination $(34 \%)$ or no treatment $(34 \%)$. Overall inpatient mortality was $43 \%$. Patients on vasopressors $(p=0.015)$, inotropes $(p=0.029)$ or combination $(p=0.002)$ were significantly more likely to die than those without treatment. Indeed, the latter group had a lower proportion of outof-hospital arrests and marginally higher SBP. Compared to no treatment, adrenaline and metaraminol significantly increased the odds ratio of in-patient death by 3.82 (CI 1.49-9.79, $\mathrm{p}=0.005$ ) and 2.9 (CI 1.23-6.97 $\mathrm{p}=0.016$ ) respectively. In contrast, there was a trend of the noradrenaline group to be lower risk (OR 0.96) albeit non-significant. There were no differences with dobutamine or dopamine. A combination of adrenaline-dobutamine was associated with increased in-patient mortality $(\mathrm{p}=0.009)$ (table 2$)$.

Conclusion This study confirms the inconsistent use of vasopressors and inotropes at the front door in patients with acute MI and CS. This needs to be more aligned to address the disparity between ESC guidance and intensivist practice. Metaraminol with its ease of use peripherally is associated with a 3 fold increase in inpatient mortality. This study also reminds us that not all ischaemic CS cases are sustained since with prompt revascularization, vasoactive agents and their associated

Abstract 61 Table 1 Baseline clinical characteristics and inhospital mortality

\begin{tabular}{|c|c|c|c|c|c|}
\hline & $\begin{array}{c}\text { Vasopressor } \\
\quad(\mathrm{n}=19)\end{array}$ & $\begin{array}{c}\begin{array}{c}\text { Inotrope } \\
(\mathrm{n}=18)\end{array}\end{array}$ & $\begin{array}{c}\text { Combination } \\
(\mathrm{n}=39)\end{array}$ & $\begin{array}{l}\text { No treatment } \\
(\quad(I=40)\end{array}$ & $\begin{array}{c}\mathbf{P} \\
\text { value }^{+}\end{array}$ \\
\hline \multicolumn{6}{|l|}{ Demographic } \\
\hline Age in years (Mean $\pm S D$ ) & $64 \pm 13$ & $76 \pm 15$ & $64 \pm 12$ & $70 \pm 13$ & NS \\
\hline Gender ( $\%$ male $)$ & $84 \%$ & $67 \%$ & $83 \%$ & $70 \%$ & NS \\
\hline BMI (Mean \pm SD) & $28.2 \pm 5.0$ & $25.8 \pm 3.9$ & $27.7 \pm 4.7$ & $27.7 \pm 5.8$ & NS \\
\hline \multicolumn{6}{|l|}{ Medical history } \\
\hline Past history of MI (\%) & $36 \%$ & $44 \%$ & $33 \%$ & $40 \%$ & NS \\
\hline Past history of HF (\%) & $26 \%$ & $33 \%$ & $10 \%$ & $10 \%$ & NS \\
\hline CKD Stage IV-V & $21 \%$ & $11 \%$ & $8 \%$ & $13 \%$ & NS \\
\hline Diabetes (\%) & $37 \%$ & $22 \%$ & $28 \%$ & $35 \%$ & NS \\
\hline Hypertension (\%) & $58 \%$ & $50 \%$ & $54 \%$ & $55 \%$ & NS \\
\hline \multicolumn{6}{|l|}{ Admission presentation } \\
\hline $\begin{array}{l}\text { Lowest SBP mmHg }{ }^{++} \\
(\text {Mean } \pm \text { SD) }\end{array}$ & $74 \pm 11$ & $69 \pm 16$ & $63 \pm 18$ & $78 \pm 13$ & 0.002 \\
\hline $\begin{array}{l}\text { Heart rate, bpm (Mean } \pm \\
\text { SD) }\end{array}$ & $89 \pm 6$ & $75 \pm 6$ & $94 \pm 4$ & $72 \pm 4$ & NS \\
\hline STEMI (\%) & $68 \%$ & $100 \%$ & $90 \%$ & $90 \%$ & NS \\
\hline $\begin{array}{l}\text { Resuscitation from } \\
\text { cardiac arrest }(\%)\end{array}$ & $58 \%$ & $22 \%$ & $51 \%$ & $20 \%$ & 0.005 \\
\hline Lactate $>2(\%)$ & $47 \%$ & $33 \%$ & $77 \%$ & $40 \%$ & NS \\
\hline Pulmonary oedema (\%) & $58 \%$ & $44 \%$ & $33 \%$ & $43 \%$ & NS \\
\hline LVEF $>50 \%(\mathrm{n}, \%)$ & $3(16 \%)$ & $2(11 \%)$ & $4(10 \%)$ & $8(20 \%)$ & NS \\
\hline LVEF $\leq 35 \%(\mathrm{n}, \%)$ & $5(26 \%)$ & $10(56 \%)$ & $17(44 \%)$ & $12(30 \%)$ & NS \\
\hline \multicolumn{6}{|l|}{ Revascularization } \\
\hline $\begin{array}{l}\text { Door to balloon time in } \\
\text { minutes) (Mean } \pm \text { SD) }\end{array}$ & $38.4( \pm 10.8)$ & $150.6( \pm 74)$ & $109.8( \pm 28.9)$ & $78.2( \pm 17.8)$ & NS \\
\hline $\begin{array}{l}\text { Triple vessel disease on } \\
\text { coronary angiography }\end{array}$ & $4(21 \%)$ & $5(28 \%)$ & $12(31 \%)$ & $16(40 \%)$ & NS \\
\hline In-hospital death, $\mathbf{n}=\mathbf{5 0}$ & $11(58 \%)$ & $10(56 \%)$ & $22(56 \%)$ & $7(18 \%)$ & 0.001 \\
\hline
\end{tabular}

